\section{Avatares de la} palabra escrita:

la notación como posibilidad narrativa. Una lectura de

Levrero, Molloy y Kamenszain

María Victoria Rupil
Licenciada en Letras por la Facultad de Filosolía y Humanidades de la Universidad Nacional de Córdoba (FFyH-UNC). Cursa el Doctorado en Letras en la mencionada Universidad. Es becaria doctoral del Consejo Nacional de Investigaciones Cientficas y Técnicas (CONICET). Su proyecto de investigación aborda las modulaciones de la escritura entendida como experiencia en obras de Clarice Lispector, Mario Levrero y Sylvia Molloy. Actualmente, se desempeña como docente adscripta en la cátedra Literatura Latinoamericana II de la Escuela de Letras (FFyHUNC). Es miembro del Proyecto de investigación "Redefiniciones de la modernidad literaria y crítica latinoamericana del siglo $X X^{\prime \prime}$, incluido en el Programa de investigación "Escrituras latinoamericanas: literatura, teoría y crítica en debate (19902010)", radicado en el Centro de Investigaciones de la Facultad de Filosolía y Humanidades (CIFFyH).

Contacto:

mariarupil@hotmail.com 
Palabras clave

Mario Levrero; Sylvia Molloy; Escribir el presente: anotarlo. Ese parece ser el lugar en el que convergen Tamara Kamenszain; notación/ los textos que, según nuestra hipótesis, construyen una zona: la de la narración, experiencia

\section{RESUMEN} notación como posibilidad narrativa y como manifestación del deseo de escribir. El presente artículo aborda esta problemática desde la lectura de tres obras de autores entendidos como casos ejemplares: La novela de la poesía de Tamara Kamenszain, La novela luminosa de Mario Levrero y Desarticulaciones de Sylvia Molloy. En los límites de las escrituras del yo, estos textos se sitúan en un umbral indefinido entre las formas de la memoria y sus modos de ficcionalización, entre la notación y la narración. Aunque existan claras diferencias estilísticas y de tradición entre los autores, esta lectura se propone indagar el horizonte común que atraviesa estas escrituras: ante el deseo y la imposibilidad de novelar, la notación surge como posibilidad narrativa.

\section{KEYWORDS}

\section{ABSTRACT}

Mario Levrero; Sylvia Molloy; Writing the present: making a note of it. According to our hypothesis, Tamara Kamenszain; notes/ that seems to be the place where some texts converge: notes as narrative; experience. a narrative possibility and as a manifestation of being willing to write. The present paper addresses this issue by examining three books we consider exemplary: Tamara Kamenszain's La novela de la poesía, Mario Levrero's La novela luminosa and Sylvia Molloy's Desarticulaciones. Within the boundaries of self-writing, these works are in an undefined threshold, between memory forms and its fictionalisation modes, between notes and narrative. Although there are some clear aesthetical and tradition differences among these authors, this paper aims to explore the characteristics these texts share: in the face of the desire and the impossibility of novelizing, notes emerge as a narrative possibility. 
AVATAReS DE LA PALABRA ESCRITA: LA NOTACIÓN COMO POSIBILIDAD NARRATIVA. UNA LECTURA DE LEVRERo, Molloy y Kamenszain

MARÍA Victoria RUPIL

El presente artículo se propone leer un corpus de textos que transitan un territorio donde la escritura, en el sentido barthesiano del término, no admite categorizaciones genéricas: ¿novela, poesía, diario íntimo, relato, escritura del yo? En estas textualidades es posible percibir, en cambio, una zona común: se configura allí una ética/estética de la notación, en la medida en que la escritura de una novela -como programa y proyecto- se ve afectada por la urgencia y el deseo de escribir. En los seminarios reunidos bajo el título La preparación de la novela, Roland Barthes afirma que:

[...] crear al otro, saber hacerlo, es el rol de la Novela. De allí, el deseo de poner la Novela como proyecto, y dar por entendido que llamo Novela no a un género históricamente determinado, sino a toda obra donde hay trascendencia del egotismo, no hacia la arrogancia de la generalidad, sino hacia la simpatía con el otro, simpatía de algún modo mimética (Barthes, 2005, 227).

Así, esta novela que es trascendencia de un yo y que aparece configurada como proyecto y no como obra cerrada, conclusa, es la idea que nos interesa resaltar: con Barthes, entendemos que no se trata de un género o una forma determinada, sino de un modo de escritura capaz de trascenderse. En este sentido, el autor agrega: "La novela aparece, entonces -al menos se me aparecía al comienzo del curso- no como una forma literaria determinada, sino como una forma de escritura capaz de trascender la escritura misma, de ampliar la obra hasta la expresión total del Yo ideal, del Yo imaginario; era 
un pro-yecto, obra hacia adelante, de allí el título del Curso: La preparación de la novela" $(2005,228)$. La novela así entendida se constituye en proyecto "imposible"; la notación traduce afectivamente el potencial narrativo de estas escrituras ya que, tal como lo entiende el autor, el deseo de escribir no vuelve hacia el pasado, sino que se instaura en el presente: "El lazo afectivo es con el presente, mi presente, en sus dimensiones afectivas, relacionales, intelectuales [...]"; y más adelante agrega: "Lo intenso es la vida presente, mezclada estructuralmente con el deseo de escribir. 'La preparación de la novela' se refiere entonces a la captación de ese texto paralelo, el texto de la vida 'contemporánea', concomitante” $(2005,53)$.

De este modo, la notación se proyecta, además, como intervención (en el sentido dialógico del término) capaz de cuestionar los modos hegemónicos de concebir lectura lescritura, pero también lo narrativo, la nota y, para el caso de Kamenszain, lo poético. A partir de esa hipótesis, es posible realizar una lectura de tres textualidades como casos ejemplares: La novela de la poesía de Tamara Kamenszain (2012), "El diario de la beca" en La novela luminosa de Mario Levrero (2005) y Desarticulaciones de Sylvia Molloy (2010).

A diferencia de la novela, que en su forma tradicional intenta escribir la historia en el relato, el tiempo de la notación es el tiempo inmediato, el de la falta, el de la pérdida. Se configura en los tres textos un acontecimiento fundamental: la escritura es experiencia, en la medida en que esa experiencia aúna en el presente la evocación, el centelleo que irradia la memoria del pasado. No se trata de recobrar el pasado en la escritura: allí se produce la experiencia, allí coinciden presente y memoria. Tal como lo entiende 
AVATAReS DE LA PALABRA ESCRITA: LA NOTACIÓN COMO POSIBILIDAD NARRATIVA. UNA LECTURA DE LEVRERo, Molloy y Kamenszain

MARÍA Victoria RUPIL

Blanchot, no se trata de narrar un acontecimiento, sino de producirlo en el relato. En el ensayo titulado "El encuentro con lo imaginario", el autor afirma:

[...] El carácter del relato no se presiente en modo alguno cuando se ve en él la narración verdadera de un acontecimiento excepcional, el cual ha tenido lugar y que se trataría de contar. El relato no es la narración del acontecimiento, sino ese acontecimiento mismo, el aproximarse de ese acontecimiento, el lugar donde éste está llamado a producirse, acontecimiento todavía por venir y gracias a cuya fuerza de atracción el relato puede esperar, él también, realizarse (Blanchot, 2005, 27).

Así, aunque existan claras diferencias estilísticas entre los autores (el verso encabalgado como voluntad narrativa en Kamenszain, el diario como posibilidad de "la novela luminosa" en Levrero, y la urgencia del escriba en el texto de pasaje de Sylvia Molloy), aparece un horizonte de búsqueda común: la pérdida -causada por la muerte, por la imposibilidad de escribir la novela o por la ausencia de memoria del otro- da lugar a la experiencia de escribir.

El problema que será abordado aquí es lo que vincula los textos de autores pertenecientes a tradiciones y lugares de enunciación diferentes. En estas obras, cabe leer la notación como posibilidad de escribir ante la pérdida. En los tres casos, a partir de vías diferentes, la notación "prepara la novela por venir", la novela que, tal como fue enunciado líneas arriba, 
es deseo y posibilidad de narrar.

El deseo de escribir propicia la experiencia de la escritura y subvierte los límites de género, ya que el fragmento como forma, la contaminación de discursos, el deseo de asir el presente y la emergencia de la memoria involuntaria confluirán como motivo primero del acto de escribir en el corpus de escrituras que serán analizadas en el presente artículo.

A continuación, trazaremos una lectura posible de las obras de Kamenszain, Levrero y Molloy a partir de dos abordajes: la notación como experiencia escritural y el deseo de escribir como fundamento de la escritura.

\section{LA POESÍA COMO NOTACIÓN: MODOS dE (¿NO?) NARRAR EN LA NOVELA DE LA POESÍA DE TAMARA} KAMENSZAIN

“¿Ya hablé de la muerte?” Así comienza el poemario La novela de la poesía de Tamara Kamenszain, texto epilogal que cierra el volumen homónimo de su poesía reunida, publicado en 2012 por la editorial Adriana Hidalgo. Esa pregunta cifra el motivo que atraviesa los poemas de las tres partes del poemario: hablar, decir, anotar la muerte es un modo de afirmar la ausencia: la voz poética de estos textos vuelve una y otra vez sobre la misma pregunta: ¿Es eso hablar de la muerte?, pregunta que suena como eco arrojado al vacío y que trae, en el ejercicio de pronunciarse, una serie de reminiscencias de lo que puede ser o no hablar de la muerte. Se construye, a lo largo de La novela de la poesía, una genealogía de poetas, una familia de voces como ausencias, de los poetas que muertos tienen voz y autoridad -ahora- para hablar de la 
AVATAReS DE LA PALABRA ESCRITA: LA NOTACIÓN COMO POSIBILIDAD NARRATIVA. UNA LECTURA DE LEVRERo, Molloy y Kamenszain

MARÍA Victoria RUPIL

muerte. La escritura en el poemario de Kamenzsain funciona como espacio del acontecimiento: ante la imposibilidad de narrar ese acontecimiento, de hablar de la muerte, aparece la posibilidad de "versificar al otro" (Kamenszain), y ese otro siempre es un poeta, ausente, ya muerto. La cita del otro, el nombre del otro, el que no vive ya, es el autorizado para decir la muerte: el yo sólo puede citar esa palabra, nacer en esa generación, escribir la vida y la muerte "en un cuaderno a rayas". La escritura, el deseo de escribir la muerte, no sobre la muerte, sino esa experiencia, el acontecimiento, es la posibilidad de habilitar un espacio literario, sostenido por una genealogía poética configurada a partir del ejercicio metaliterario.

El espacio ocupado por esa genealogía que funciona como "la generación" es el espacio de la escritura: ¿dónde habitan los muertos, las voces de los muertos, si no es en sus versos? La voz poética de este poemario configura ese espacio de acceso de las voces que, aunque ausentes, todavía suenan. La cita de algunos pasajes servirá para ilustrar este aspecto:

[...]

Dejé anotado que se fueron

les dediqué libros los nombré por sus nombres me anoticié de que nadie me contestaba. ¿Eso es hablar de la muerte? Ensayé todo lo que pude insistí con estribillos ajenos 


\author{
"debajo estoy yo" "debajo estoy yo" \\ pero Pizarnik ya había nacido \\ enterrada Alejandra Alejandra \\ se hizo llamar desde chica \\ y eso sí es hablar de la muerte. \\ Yo solamente la cito \\ porque nací en una generación \\ y eso no es hablar de la muerte \\ [...] (Kamenszain, 2012, 373).
}

Aquí, en estos versos, es posible rastrear una serie de verbos del decir que suplen la respuesta a la pregunta que abre esta primera parte: hablé, dije y digo, hablar, dejé anotado, dediqué, nombré, ensayé, insistí, cito. Cumplen el lugar fantasmático de la imposibilidad que tiene la palabra para asir la muerte, ese instante sagrado de pasaje. El espacio de la escritura es capaz de dotar de sentido la palabra del otro al versificar al que versificó -que hablóde la muerte. Alejandra Pizarnik, Viel Temperley, Perlongher se cruzan como versos con el decir de la genealogía familiar: "murió mi hermano/murieron mis padres/ murió el padre de mis hijos". Se entreveran las voces que dijeron la muerte con las voces que mintieron la muerte. Viel, Alejandra, Perlongher muriendo fueron capaces de nombrar ese instante; la voz poética se asume en el lugar de la incapacidad de decirla, como los padres que mintieron la muerte para no hacer daño: "Mis padres me mintieron para que no sufriera/ ahora la que miente soy yo" $(2012,374)$. 
AVATAReS DE LA PALABRA ESCRITA: LA NOTACIÓN COMO POSIBILIDAD NARRATIVA. UNA LECTURA DE LEVRERo, Molloy y Kamenszain

MARÍA Victoria RUPIL

$[\ldots]$

los que nacimos en una generación

seguimos jugando con palabras

como si tuviéramos toda la vida

por delante un cuaderno a rayas

por detrás nuestros muertos queridos

hay que seguir hay que seguir

me digo como a mi edad

se suele decir la gente

cuando habla sola

para no hablar de la muerte $(2012,375)$.

Escribir poesía, se pregunta esta voz, (¡eso es hablar de la muerte?), entre paréntesis, como excepción, porque la ficción, la novela no es capaz de hacerlo. Por eso, para no escribir una novela, se escribe la novela de la poesía. Se trata de una novela sobre la palabra poética que configura una generación y que es configurada por ella: una genealogía literaria de "muertos autorizados" para hablar de la muerte. Es posible leer en el poema:

$[\ldots]$

llevo un diario de los días que vuelan

miro hacia atrás miro hacia adelante

es el lujo que me doy en el secreto

si lo guardo termino hablando de nada 
si lo ventilo tengo que inventar una novela y eso no es hablar de la muerte $(2012,376)$.

Hay que destacar los últimos versos de este pasaje: ventilar el secreto es inventar la novela: la narración, según la perspectiva poética, no es capaz de albergar el secreto, necesita inventar, ficcionalizar. Aparece aquí una jerarquización, un valor primero, anterior, del verso y la palabra poética. Esta última, por constituirse ella misma en acontecimiento, es capaz de revelar el instante presente en la actualidad de lo inmediato, inmanente. La poesía se escribe, "mira hacia atrás mira hacia adelante", se concibe ella misma como acontecimiento, es experiencia en el sentido batailleano del término. En relación a la poesía, el filósofo francés afirma: "Nada es más esencialmente perecedero que lo sagrado o lo poético, que poseen al mismo tiempo la plenitud y la inasible brevedad del instante" (Bataille, 2008, 55). Es necesario resaltar aquí el valor coincidente entre lo sagrado y lo poético: poseer concomitantemente la plenitud y la brevedad del instante. Esta idea se acerca al estudio de Barthes sobre la forma poética mínima, el haiku². En la escritura del presente emerge, de este modo, la memoria involuntaria que deviene experiencia: el poema es la experiencia singular $y$, tal como la entiende Lacoue-Labarthe, por ser una experiencia singular,

${ }^{2}$ En La preparación de la novela, Barthes esboza su teoría sobre la notación y la narración a partir del estudio de dos modos literarios, que funcionan como pivotes de su análisis. Por un lado, la lectura de la forma poética japonesa breve, el haiku, y por el otro, la lectura ejemplar de la novela a partir de Proust. Allí, en relación a la notación en su lectura del haiku, afirma: "Haiku= forma ejemplar de la Notación del Presente= acto mínimo de enunciación, forma ultra breve, átomo de frase que anota (marca, limita, glorifica: dota de una fama) un elemento tenue de la vida 'real', presente, concomitante." $(2005,59)$. 
AVATARES DE LA PALABRA ESCRITA: LA NOTACIÓN COMO POSIBILIDAD NARRATIVA. UNA LECTURA DE LEVRERO, MOLlOy y KamenSZain

María Victoria RuPIL

también es una experiencia de memoria (Lacoue-Labarthe, 2006, 31) ${ }^{3}$.

Si la poesía puede concebirse como forma de escritura capaz de decir la muerte es justamente por eso, porque es acontecimiento y como tal no necesita re-construir el pasado ni forzar lo que vendrá, porque como acontecimiento es pleno al mismo tiempo que es capaz de capturar la inminencia del presente: por eso los muertos autorizados dicen la palabra poética "muriendo", en ese instante umbral que es, también, el momento de la enfermedad o la muerte. En este sentido, en el prólogo a La novela de la poesía, Enrique Foffani refiere:

[...] el yo que habla en el poema, sabe que no hay representación posible de la muerte y que la muerte es siempre una experiencia del otro, una otredad que, paradojalmente, solo puede ser dicha por un yo-testigo en su situación de sobrevivencia; y, de otra parte, porque muestra en su desnudez lo que significa la imposibilidad de decir la muerte, lo que el poema decide decir con un demostrativo que solo puede convocar el ensayo, la aproximación o un eco que viene de los poetas que ya pasaron por esa experiencia sin retorno y que intentaron, por todos los medios, decir y escribir (en) el límite mismo entre la vida y la muerte (Foffani, 2012, 10).

\footnotetext{
3 En su lectura de dos poemas de Paul Celan, Lacoue-Labarthe sostiene que el poema es una experiencia singular que es "puro-querer-decir": para el autor no se trata de entender la experiencia poética como una vivencia, sino a partir de lo que queda suspendido, en espera (29). En este sentido, su lectura le otorga al vértigo el lugar de la experiencia y de la memoria: "[...] El vértigo actúa, en este caso, como el índice de este inadvenimiento del que la memoria, más que como simple recuerdo, deviene paradójica restitución. El vértigo es memoria, porque toda verdadera memoria es vertiginosa al ofrecer la propia atopía de la existencia [...]” (32).
} 
Si la primera parte del poemario inaugura una serie de poetas a los que la voz poética suscribe, la constelación poética de la segunda se extiende, aparecen otros nombres: Osvaldo Lamborghini, Rimbaud, César Vallejo, Gambarotta (el "vivo muerto"), Amelia Biagioni. A partir de aquí se nombra -se dota de nombre- "el límite": el poeta autorizado es capaz de decir lo que el juego poético no puede.

Cuando el último día de un seminario

les leí a mis alumnos esos versos de él

que dicen:

"Nací en una generación.

La muerte y la vida estaban

En un cuaderno a rayas"

quise regalarles un momento autobiográfico

una foto de época donde se abriera

la evidencia de la imagen como enseńanza realista

pero también en estado de power point

quise proyectar entre ellos y yo

un pacto de autoridad que hable por mí

de lo que yo no puedo hablar:

de la muerte

de los que no están más

del tiempo que pasa $(2012,383)$. 
AVATAReS DE LA PALABRA ESCRITA: LA NOTACIÓN COMO POSIBILIDAD NARRATIVA. UNA LECTURA DE LEVRERo, Molloy y Kamenszain

MARÍA Victoria RUPIL

La cita del poeta traduce -con total autonomía y prescindiendo de recursos narrativos- la inmanencia de la palabra poética, que revela en su totalidad el acontecimiento signado por el hecho de pertenecer a una generación (a un momento histórico, pero también a una genealogía poética), así el poeta es capaz de escribir la muerte. Los versos encabalgados cantan aquello que la narración no es capaz de contar. En este sentido, y en relación a la posibilidad de "poner en palabras la muerte", Adriana Kanzepolsky refiere:

[...] lo que el poemario despliega es una extensa escena de lectura o, más puntualmente, la imagen de alguien -un sujeto de la enunciación- que se pone en el lugar de una lectora. Alguien que lee los textos de otros pero también, y tal vez por sobre todo, sus propios textos, alguien que lee las operaciones que viene realizando desde 2003 en un intento por poner en palabras la muerte y el duelo (Kanzepolsky, en prensa, 14) ${ }^{4}$.

La palabra poética escenifica un estado de las cosas y proyecta en "un momento autobiográfico" de lectura su propio valor experiencial. "Los estribillos" ajenos de los poetas autorizados cantan ese estado de las cosas: "debajo estoy yo", "hay cadáveres", "el cadáver lleno de mundo”, "es lo que hay es lo que hay es lo que hay", "eso ya fue eso ya fue eso ya fue". El ritmo se agolpa en el verso, en el eco reminiscente de los estribillos y en la fuerza del corte de los versos encabalgados de Kamenszain. El valor de la interrupción, del corte del verso, también señala ese espacio límite, umbral,

${ }^{4}$ Fue consultada la versión en castellano facilitada por la autora. 
que constituye la plenitud y la brevedad de la palabra poética. El corte traduce la imposibilidad de narrar la muerte. Así, una poética (un modo de concebir la poesía) emerge de los versos de esta segunda parte al afirmarse sobre la aseveración: "porque esto no es ninguna novela" (2012, 384).

La prosa poética ya fue

la novela lírica con evocaciones de infancia

ya fue ya fue ya fue

la poesía que se las da de narrativa

también ya fue salvo cuando cuenta.

El último poema que escribió $\mathrm{O}$. L.

es un epitafio que termina diciendo

"No escribió/ poesía / sin / embargo/

la tenía// Toda adentro: igual / desdeñoso /

impertérrito / NO /

ELEGÍA” $(2012,385)$.

El epitafio que anuncia como pasado lo que está por venir, no es, tal como lo entiende Kamenszain con Lamborghini, un modo de "escribir poesía”. $\mathrm{Al}$ menos no es la poética que el texto configura. Se trata más bien de lo que Florencia Garramuño entiende como "el paso de prosa" $(2015,146)^{5}$.

5 Florencia Garramuño sostiene que la pulsión que coloca a La novela de la poesía en ese lugar indeterminado entre novela y poesía está presente desde los primeros títulos de la obra de Kamenszain. La autora afirma que los pasos de prosa son "[...] momentos en los que la poesía, al atraer y convocar a ese otro de sí que es la prosa, elabora un movimiento en el que su identidad queda turbada, en equilibrio tenso con su otro" $(2015,146)$. 
AVATAReS DE LA PALABRA ESCRITA: LA NOTACIÓN COMO POSIBILIDAD NARRATIVA. UNA LECTURA DE LEVRERo, Molloy y Kamenszain

MARÍA Victoria RUPIL

"La novela de la muerte", tercera parte del poemario, configura ya una poética - una ética/estética de la poesía- y lo hace ensayando sobre el primer narrador que aparece entre los nombres de la serie poética que configura $\mathrm{La}$ novela de la poesía.

\author{
Cuando ganó la beca Guggenheim \\ para escribir La novela luminosa \\ Mario Levrero empezó escribiendo \\ "El diario de la beca" \\ para no escribir La novela luminosa $(2012,391)$.
}

Hay que destacar el aspecto que señalan los versos que abren la tercera parte, ya que el diálogo que se establece con Levrero hace emerger una cuestión fundamental que atraviesa los textos de los tres casos que abordamos en este artículo: ante la imposibilidad de novelar, la notación surge como una forma de escritura literaria, capaz de instaurarse como experiencia inmediata, al decir de Bataille, otra vez, asentada sobre la plenitud y la brevedad del instante. Aparece de nuevo aquí la idea de diario, del cuaderno a rayas, donde el autor escribe, con fecha y hora, anota la intensidad o la vacuidad del presente. Blanchot sotiene que "el diario arraiga el movimiento de escribir en el tiempo, en la humildad de lo cotidiano fechado y preservado por su fecha” (Blanchot, 2002, 25), lo que interesa para el diario justamente es la posibilidad de escribir el movimiento, el tiempo inmediato, sumergirse en el acontecimiento cotidiano. No importa tanto qué escribe, sino el modo 
de hablar "de un hombre que no quería narrar". La preparación de la novela, postergada, inconclusa y póstuma de un escritor que:

\author{
Sólo quería regalarnos minuto a minuto \\ el ritmo obsesivo de una rutina \\ el estribillo del encierro un poema \\ de 500 páginas $(2012,391)$.
}

Cabe preguntarse: ¿en qué medida, por qué el narrador/ escritor es concebido por Kamenszain como autor de "un poema de 500 páginas"? Cabe no responder también, pero arriesgamos: la experiencia de la escritura del "Diario de la beca" encierra en sí misma el valor poético de la palabra que se sabe incapaz de decir, de hablar de, si no es a cuenta de pronunciar esa imposibilidad. ¿Es la cercanía de la muerte lo que autoriza al autor de este diario/ poema a hablar de la muerte? ¿Es el carácter autobiográfico de esta narrativa que se trama sobre la urdimbre del terreno biográfico? Entre la vida y la muerte se funda el acontecimiento de la escritura poética que es pregunta abierta, pregunta eco, resuena cual estribillo. El deseo de narrar se ve interrumpido por la posibilidad de la notación: la anotación es capaz de albergar, "de tener adentro", toda la poesía y toda La novela luminosa. La alusión y el "ensayo" sobre Levrero terminan de plasmar una cartografía poética, una epístola cifrada en La novela de la poesía. Así como la conclusión del poemario se cierra con una alusión a los versos de Vallejo, 
AVATARES DE LA PALABRA ESCRITA: LA NOTACIÓN COMO POSIBILIDAD NARRATIVA. UNA LECTURA DE LEVRERO, Molloy y Kamenszain

MARÍA Victoria RUPIL

"Entre el dolor y el placer..."6, todo el poemario de Kamenszain anota -entre la cita, la alusión, el nombre, la forma de los versos, la repetición, el corte, el fragmento- un espacio de valor, un espacio que quiere "seguir contando", que es la experiencia de una lectura devenida escritura, epístola -entre la muerte y la vida, "entre el dolor y la alegría"- que puede valerse de modos otros de narrar.

\section{LA EXPERIENCIA dE LA NOTACIÓN ANTE EL DESEO IMPOSIBLE dE ESCRIBIR LA NOVELA LUMINOSA: "EL} diario de LA beCA" de MARIO LeVreRo

Tal como apunta el poemario de Kamenszain, Mario Levrero recibe en el año 2000 una beca de la Fundación Guggenheim para corregir los capítulos escritos y concluir la escritura de su proyecto "inconcluso y póstumo", $\mathrm{La}$ novela luminosa. En este proyecto, pretendía narrar una serie de experiencias personales trascendentales que él denominaba "luminosas". La referencia a la escritura de esta novela aparece en reiteradas ocasiones, ya desde el año 1986, pero también el proyecto y la imposibilidad de terminar de escribirlo se reitera como motivo en innúmeras entrevistas. Es necesario transcribir algunos de los pasajes en que el autor refiere la escritura de la novela.

\footnotetext{
6 "Entre el dolor y el placer..." de César Vallejo se publicó en los Poemas en prosa, antología póstuma del poeta peruano. Por señalar la coincidencia que arroja sobre el final del poemario de Kamenszain, en este diálogo constelado que instaura al novelar la lectura de la poesía, cito la última estrofa de estos versos: "Al sentido instantáneo de la eternidad/ corresponde / este encuentro investido de hilo negro, / pero a tu despedida temporal, /tan sólo corresponde lo inmutable, / tu criatura, el alma, mi palabra" (Vallejo, 1983, 28).

7 En su Diario de un canalla, comienza la primera entrada, con fecha 3 de diciembre de 1986, con la siguiente frase: "Han pasado más de dos años; casi tres desde que empecé a escribir aquella novela luminosa, póstuma, inconclusa" (Levrero, 2013, 17).
} 
Antes que eso, cuando estuve en Uruguay empecé una novela cuyo título era Novela luminosa... Un rescate autobiográfico de los momentos de mayor luminosidad, espiritualidad. Después, se comenzó a mezclar con cosas más turbias... con estilo "no literario" digamos, muy suelto. [...] Además pienso que es impublicable por lo que toca a otras personas (Entrevista de 1983 en Gandolfo, 2013, 69).

Estoy penosamente tratando de terminar algunas cosas inconclusas como $\mathrm{La}$ banda del ciempiés cuyo adelanto ya fue publicado en Buenos Aires. También una especie de autobiografía selectiva que comencé a trabajar en 1984 que estoy limando para que sea publicada en vida (Entrevista de 1993 en 2013, 109).

Recién por 1984 comencé a sentir una imperiosa necesidad de escribir a mano; en los sueños me veía escribiendo a mano. Pero estas imágenes están incluidas en el texto sobre el cual estoy retornando ahora, una novela que quedó inconclusa, y no debo hablar del tema (Entrevista de 2000, en 2013, $150)$.

"Rescate autobiográfico", "especie de autobiografía selectiva”, "novela inconclusa": en las entrevistas, el autor asume el proyecto al mismo tiempo como novela y como autobiografía. No importa tanto para nosotros -parece que tampoco importa para el autor- encasillar esta obra en un género, pero sí asumir que se trata de un proyecto postergado, que admite el rasgo 
AVATAReS DE LA PALABRA ESCRITA: LA NOTACIÓN COMO POSIBILIDAD NARRATIVA. UNA LECTURA DE LEVRERo, Molloy y Kamenszain

MARÍA Victoria RUPIL

autobiográfico y que se define, a la vez, como novela. Suenan de nuevo los versos de Kamenszain:

\author{
Diario, autobiografía, blog, narrativa en primera \\ o como se quiera llamar ese cuaderno éxtimo \\ que la muerte del autor transformó en libro. \\ ¿Es novela? ¿Es el protagonista/ igual al narrador igual al autor igual \\ a un hombre como cualquier otro lleno de manías? \\ bañarse poco comer mal no escribir no escribir \\ que la narrativa no cuente \\ que la poesía cuente si no cuenta $(2012,391)$.
}

Si la novela no es capaz de contar, si la novela se asume incapaz de narrar, entonces se activa la visión de diario, "de cuaderno a rayas", "la necesidad de escribir a mano", la notación como posibilidad narrativa. "El diario de la beca”, ese extenso poema de 500 páginas, como lo denomina Kamenszain, conduce al posible lector a adentrarse en los recovecos intestinos de un autor que intentó escribir la muerte al escribir la vida, al notar -en los dos sentidos del término, como notación y como descubrimiento- que ciertas experiencias son imposibles de contar, y que la palabra, por no poder transcribir la experiencia, debe ensayar modos de capturar la memoria de las experiencias trascendentales pretéritas al escribir el presente.

En el "Prefacio histórico" al libro, el autor plantea que, de acuerdo con sus ideas, "ciertas experiencias extraordinarias no pueden ser narradas sin 
que se desnaturalicen; es imposible llevarlas al papel” (Levrero, 2010, 13) y concluye el mismo texto: "La tarea era y es imposible. Hay cosas que no se pueden narrar. [...] Los hechos luminosos, al ser narrados, dejan de ser luminosos, decepcionan, suenan triviales. No son accesibles a la literatura, o por lo menos a mi literatura" $(2010,19)$. Esa imposibilidad de escribir lo lleva a concebir la escritura del extenso prólogo a la novela, "El diario de la beca", cuyo objetivo fundamental era el de "poner en marcha la escritura, no importa con qué asunto, y mantener una continuidad hasta crearme el hábito" (2010, 23). Como vimos líneas arriba, escribir el diario, en su voluntad de narrar las experiencias luminosas, implica un ejercicio que se sostiene por la notación continua de acontecimientos cotidianos -o el recuerdo inmediato, involuntario de acontecimientos pasados- que suscitan la emergencia involuntaria, finalmente, de la narración del acontecimiento pretérito, extraordinario, luminoso. Blanchot afirma: "El interés del diario radica en su insignificancia. [...] Cada día nos dice algo. Cada día anotado es un día preservado. [...] Así nos protegemos del olvido y de la desesperación de no tener nada que decir" $(2005,221)$. Ante la imposibilidad de escribir la novela, Levrero anota el día para resguardarlo: cuando anota que no puede escribir, escribe. Sobre esto, el narrador de "El diario de la beca" enuncia: "Escribir diariamente sobre los sucesos frescos es un error. Por lo general, las cosas interesantes me vienen a la memoria al otro día [...] la anotación inmediata es una referencia, pero es difícil transmitir el hecho vívido porque no ha habido elaboración [...]" (2010, 325).

"El diario" se trama sobre un fondo fragmentario: lo que le da unidad 
AVATAReS DE LA PALABRA ESCRITA: LA NOTACIÓN COMO POSIBILIDAD NARRATIVA. UNA LECTURA DE LEVRERo, Molloy y Kamenszain

MARÍA Victoria RUPIL

al relato del diario es la inmediatez datada, la continuidad de una voz narrativa figurada en el personaje autobiográfico del narrador. Se escribe a partir de entradas, fragmentos que construyen, finalmente, la narración de la "imposible narración" de La novela luminosa.

La ruptura de la obra como sistema cerrado posibilita el surgimiento del libro como aquello que está por venir (2005): el diario de la escritura de la novela que vendrá. Como en las obras de Kamenszain y de Molloy, la notación constituye un umbral entre dos espacios (el poético o ficcional de la literatura y el biográfico del diario). En los tres casos, el límite entre esos espacios se reconfigura en otro modo de escribir, que a la vez lo supera y lo cuestiona: el fragmento es la forma de narrar el presente. De esta manera, lo fragmentario implica a la vez lo que está fuera del texto -aquellos trechos que conforman lo que escapa al decir, al narrar- ${ }^{8}$, pero lo fragmentario además es la forma que asume el relato. En relación a esta idea de lo fragmentario y el tiempo, Blanchot afirma que es la experiencia del instante lo que conduce a la separación y a la dispersión: "Unirse a la dispersión, a la intermitencia, al brillo fragmentado de las imágenes, a la fascinación centelleante del instante, es un movimiento terrible; una dicha terrible, sobre todo cuando, finalmente, ha de dar lugar a un libro" (2005, 131) (el resaltado me pertenece).

En "El diario de la beca" convergen, de este modo fragmentario y disperso, las vicisitudes cotidianas de un escritor en proceso de escribir, obligado por

${ }^{8}$ Será, por ejemplo, la imposibilidad de hablar sobre la muerte en Kamenszain; la imposibilidad de narrar, de escribir la novela luminosa en Levrero y, en el caso de Molloy, estará dado por la imposibilidad de reconfigurar una experiencia común a partir de la pérdida de la memoria del otro. 
poseer una beca a concluir una novela que le es imposible escribir; y también el diario está surcado por la narración de otra novela que configura a lo largo del texto una historia referenciada con principio, nudo y final: la historia de la paloma muerta en la terraza. La escritura del suceso de la paloma atraviesa gran parte del relato del diario y funciona como alegoría de la vida y de la muerte: narrar la muerte y la descomposición de "la paloma muerta", las visitas de la "viuda", la aparición de los pichones. Ante la dificultad para escribir la novela surge el relato de un suceso exterior que se construye como imagen que, aunque aparenta ser otra de las trivialidades cotidianas, configura una visión posible de la naturaleza, de la vida y de la muerte. La trascripción de la narración del suceso de la paloma ocuparía una buena cantidad de páginas; ilustraremos entonces el relato aludiendo solamente a la primera mención y al final de la historia, que coincide a la vez con el punto final del diario:

Al levantar la persiana del dormitorio, vi una vez el cadáver de una paloma en una azotea muy próxima a este edificio. Lo había visto ya hace unos días, y volví a verlo más recientemente, y en esa segunda oportunidad había visto a la pareja de la paloma muerta en actitud de velorio, parada muy quieta a uno o dos metros del cuerpo, de espaldas a mí, mirando fijamente al muerto. $\mathrm{O}$ quién sabe adónde, porque cuando una paloma quiere mirar algo de frente pone la cabeza de costado, como los bizcos. [...] Sin saber si esto será fiel a la verdad, voy a designar a la paloma viva como la "viuda", asumiendo que el cadáver es un macho $(2010,146)$. 
AVATARES DE LA PALABRA ESCRITA: LA NOTACIÓN COMO POSIBILIDAD NARRATIVA. UNA LECTURA DE LEVRERO, MOLlOy y KamenSZain

MARÍA Victoria RuPIL

Jueves $2,03.18$

Un objeto raro que había cerca de la paloma muerta resultó ser, visto a la rara luz del sol una rara tarde en la que salió el sol, y en la que yo estaba despierto para ver su luz, resultó ser, decía, la cabeza de la paloma; es decir, la calavera. [...] La cabeza de una paloma sin plumas ni carne es casi puro pico, enorme en relación con el cráneo. Con razón son tan estúpidas (2010, 451).

El final de "El diario de la beca" coincide con el final de la historia de la paloma muerta: nos preguntamos con Kamenszain, ¿será eso hablar de la muerte? Anotar la muerte del otro es un modo de decir la muerte en Levrero, es necesario cerrar la historia de la visión de la paloma para terminar de escribir el diario. Esto no clausura La novela luminosa, sino que esa visión posibilita el surgimiento del libro y se transforma en motivo final de la escritura. La notación en Levrero funciona como ensayo de lo que es actual, inmediato y de lo que es imposible de escribir: si algunas experiencias trascendentales no se pueden narrar, la visión del presente puede ser notada, anotada y deviene, de manera involuntaria, en la narración de la experiencia luminosa?

\footnotetext{
9 En una de las entrevistas compiladas por Gandolfo, publicadas en 2013 por Mansalva, podemos rastrear en el transcurso de los años una voluntad de construir una "poética", una serie de ideas que configuran a lo largo de los años una visión sobre la escritura en Levrero. En algunas de estas entrevistas, el autor se dedica a elaborar una concepción de la literatura y de su experiencia de escribir. Sobre la escritura de las experiencias trascendentales y los modos posibles que halló para narrarlas, afirma el autor en "Una entrevista imaginaria de Mario Levrero por Mario Levrero: "Este último año ha sido bastante parecido a un año. De cualquier manera, al estar en cierto modo divorciado de mi 'inconsciente', toda experiencia, aún la de apariencia más compleja y atractiva, la siento incompleta, como que me estoy perdiendo algo esencial. Hubo una serie de experiencias notables, a las que por suerte pude rescatar, 'darles consistencia', escribiendo o bien breves pasajes, tipo diario íntimo, o bien cartas a algunas amistades, pero es todo muy fragmentario y muy 'actual', me está faltando la
} 
En síntesis, es posible afirmar que "El diario de la beca" anota la imposibilidad de la escritura de La novela luminosa y, al mismo tiempo, en el acto de anotar esa imposibilidad, da lugar al libro: el diario del proceso de la experiencia creativa desarma la idea de obra en la escritura de la novela inconclusa, que parece volver sobre sí misma en un movimiento incesante, circular ${ }^{10}$.

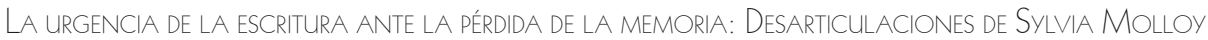

“Tengo que escribir estos textos mientras ella está viva, mientras no haya muerte o clausura, para tratar de entender este estar/ no estar de una persona que se desarticula ante mis ojos" (Molloy, 2010, 9), tal el comienzo, la apertura de Desarticulaciones. Libro que se abre con una urgencia: escribir es anotar rápidamente lo que queda antes de que termine de "desarticularse" el otro: el narrador escribe sobre el proceso de pérdida de memoria del personaje, M.L.

Desarticulaciones, en ese sentido, es un paréntesis: entre la palabra articulada, el lenguaje supuestamente capaz de decir, rememorar, y la

literatura (Entrevista de 1992 en 2013, 98-99).

${ }^{10}$ En relación al sentido inacabado o fracasado de la obra en La novela luminosa, en una lúcida lectura desde la inoperancia, Matías Oviedo seńala: "El proyecto de Levrero es, dijimos, imposible: hacer coincidir vida y escritura, crear una obra inoperante, narrar experiencias inefables y vivir de acuerdo a las mismas. Su imposibilidad no la hace, sin embargo, una empresa vana; cabe preguntarnos aquí cuántos proyectos literarios del pasado fueron imposibles, inabarcables, infinitos. No parecería erróneo afirmar que son numerosos los proyectos literarios inconclusos, fracasados y/o imposibles que han escrito páginas importantes en la historia de la literatura. Asimismo, podría decirse que Levrero clausura la posibilidad del fracaso ya que la inoperancia va en contra de la dialéctica productiva. La escritura actúa aquí como una potencia que se resiste a terminar de realizarse, la completud deja de ser un horizonte" (Oviedo, 2014, 111). 
AVATAReS DE LA PALABRA ESCRITA: LA NOTACIÓN COMO POSIBILIDAD NARRATIVA. UNA LECTURA DE LEVRERo, Molloy y Kamenszain

María Victoria RupiL

escritura de la des-articulación del mismo lenguaje y de la memoria. Ya en su libro de 1981, En breve cárcel, la narradora señalaba: “¿Cómo anotar, cómo escribir alguna vez la unión salvo en función de la ausencia?” (Molloy, 2011, 120).

En el caso que nos ocupa, la ausencia progresiva de una memoria que va perdiendo la capacidad de relación, de vínculo, de unión: la palabra escrita interrumpe ese momento de "desarticulaciones". La experiencia de anotar al otro, escribirlo, intenta sostenerlo antes de que termine de desarticularse. En este sentido, es lo que permite anclar el presente que evoca los recuerdos compartidos que, por el vacío de memoria del otro, parece desintegrarse paulatinamente, perderse. Es un texto que, según la lectura de Kanzepolsky (2014), se escribe en el mientras tanto: M. L. no ha desaparecido completamente, pero el abandono de la memoria la ha convertido ya en una ruina.

La ausencia del otro - la ausencia de su memoria capaz de construir el recuerdo compartido- conlleva la búsqueda de esta escritura inmediata, esta experiencia que intenta asir el débil hilo que todavía vincula a los personajes del relato. La escritura se asienta sobre el resto de la memoria que queda y vuelve continuo lo discontinuo, intenta articular la desarticulación (del otro, del lenguaje y de la memoria). Dirá la narradora de este relato: "No escribo para remendar huecos y hacerle creer a alguien (a mí misma) que aquí no ha pasado nada, sino para atestiguar incoherencias, hiatos, silencios. Esa es mi continuidad, la del escriba" $(2010,38)$.

La única continuidad del interrumpido relato de la pérdida se asienta 
sobre el hacer del escriba. La escritura no es capaz de "remendar", de llenar los vacíos, de decir los silencios: quien escribe solo puede dar cuenta de esos vacíos, funciona al nivel del testigo, observador que no puede ni debe intervenir, sino mostrar la elipsis instaurada por el silencio y la presencia ausente del otro.

Tamara Kamenszain sostiene que la escritura de Molloy está signada por "el espíritu de la notación"11. En este sentido, debemos referir el diálogo que se establece entre Desarticulaciones y el poemario de Kamenszain, El eco de mi madre. Ambos se escriben a partir de la voluntad de anotar la ausencia presente que imparte sobre la memoria del ser querido el Alzheimer:

Como mi madre que a veces me trata de usted

y yo me doy vuelta para ver quién soy,

la amiga de Sylvia que perdió el voseo

la desconoce hablándole de tú.

Correctas educadas casi pomposas

estas rehenes del Alzheimer

ponen a congelar la lengua materna

mientras nos despiden de su mundo sin palabras.

Sin embargo si te canto tu canción infantil

la neurona del idisch se posa dulce sobre tus labios

y todo lo que nunca entendí en ese idioma

lo repito con vos viejita, y me queda claro (Kamenszain, 2012, 350).

${ }^{11}$ La autora se refirió a este aspecto en la Conferencia realizada en la Universidade de São Paulo en 2012, titulada "Narrarse a sí mismo, versificar al otro. Los casos Molloy- Kamenszain". 
AVATAReS DE LA PALABRA ESCRITA: LA NOTACIÓN COMO POSIBILIDAD NARRATIVA. UNA LECTURA DE LEVRERo, Molloy y Kamenszain

MARÍA Victoria RUPIL

La lengua, la palabra, es el lugar de encuentro con el otro: la mirada desconocedora del otro, la palabra que es incapaz de reconocerlo resulta una pregunta por la identidad de uno mismo. La palabra se encuentra, en este sentido, con los lugares de pertenencia de la infancia, del tiempo remoto donde la lengua materna funcionaba como patria. La complicidad de las miradas sobre el uso común de la lengua se va perdiendo: lengua, infancia y patria dejan de constituir el lugar de encuentro de la memoria compartida. En este sentido, la narradora anota: "Al hablar con ella me siento -o me sentía- conectada con un pasado no del todo ilusorio. Y con un lugar: el de antes. Ahora me encuentro hablando en un vacío: ya no hay casa, ya no hay antes, sólo cámara de ecos" $(2010,73)$.

Tanto el poema de Kamenszain como el relato de Molloy convergen en el deseo de anotar el instante inmediato de la pérdida, ese momento de pasaje entre la pérdida de memoria (que es también la pérdida de la voz, de la palabra y finalmente de la lengua común) y la muerte (como ausencia, abandono y ruina del otro). En la novela de Molloy, el ejercicio de la notación funciona como ancla del presente y se acerca, en el nivel formal y de contenido, a la particularidad del diario: los fragmentos funcionan como el registro diario del encuentro con el otro. Tal como fue señalado líneas arriba, al perder la memoria compartida, el presente se vuelve extrańo para aquel que lo percibe y produce el desencuentro: "Y porque para mantener una conversación - para mantener una relación-es necesario hacer memoria juntas o jugar a hacerla, aun cuando ella -es decir, su memoria- ya ha dejado sola a la mía” $(2010,33)$. 
La urgencia de la notación permite no olvidar, funciona al modo de las listas que remiten siempre al sujeto que las escribe y que las codifica, listas que sin su interpretación, no tienen sentido $(2010,34)$. La notación activa el recuerdo: el del encuentro inmediato, pero también el de la memoria de los sucesos pasados que se vuelven extrańos si no pueden ser rememorados por los protagonistas de ese recuerdo.

El ejercicio de anotar vincula la experiencia y la memoria al acto de la escritura urgente. En este sentido, es posible pensar con Saer que experiencia y memoria aparecen estrechamente ligadas en la escritura: "Experiencia y memoria son inseparables. Escribir es sondear briznas o astillas de experiencia y de memoria para armar una imagen determinada, del mismo modo que con pedacitos de hilos de diferentes colores, combinados con paciencia, se puede bordar un dibujo sobre una tela blanca" (Saer, 1986, 17). La escritura que se trama sobre la memoria y la experiencia, la experiencia que se trama en la escritura y que aparece urdida, también, por la memoria, parece ser el paréntesis que escribe Desarticulaciones. La imagen que se borda, que se arma a partir de las astillas de la experiencia y de la memoria, en este texto, se traduce en el relato fragmentario del encuentro con la ruina del otro; se trata de un tejido textual que se escribe en el intersticio de ese instante que, cual hilo de muy tenue color, está a punto de cortarse. La memoria personal, en su unicidad y sin testigos que doten de otros sentidos posibles el acontecimiento pasado, queda abandonada ante la página en blanco. Si la escritura no puede recuperar la experiencia compartida, al menos será capaz de atestiguar el hiato que se dibuja entre la voz de la narradora y el otro. 
AVATAReS DE LA PALABRA ESCRITA: LA NOTACIÓN COMO POSIBILIDAD NARRATIVA. UNA LECTURA DE LEVRERo, Molloy y Kamenszain

MARÍA Victoria RUPIL

En este sentido, la notación sirve para no olvidar, para situar un tiempo y un espacio en el presente de la falta, que es el asidero último de la escritura.

\section{ALGUNAS REFLEXIONES FINALES}

A modo de cierre, es imprescindible apuntar que la lectura propuesta en este artículo no agota los sentidos posibles de las textualidades analizadas: las preguntas que giran en torno a la lectura de estos casos no terminan de responderse en estas páginas, abren en cambio una serie de nuevas preguntas, posibles nuevos recorridos. Así, es necesario afirmar que estas escrituras de Kamenszain, Levrero y Molloy parecen atravesar una senda de búsqueda común: se trata en los tres casos de textos umbrales que diluyen los límites entre géneros y que sitúan la subjetividad (sujeto lírico, narrador o escriba) en el centro del relato. Escrituras que anotan el presente, que giran en torno a los sucesos inmediatos de un yo, y que se inscriben en el límite entre diario, poesía, monólogo interior, novela. El ejercicio de la rumiación del presente activa la memoria involuntaria, que emerge en estos relatos a partir de la notación, como gesto y deseo de escribir.

En los textos de los tres autores, la escritura es el intento de asir aquello que queda fuera, lo que no se puede escribir: hablar de la muerte en Kamenszain, la voluntad de captar la luminosidad de la experiencia en Levrero, el intento por capturar el hiato entre memoria/ pérdida de la memoria en Molloy. Albergan en su seno la posibilidad de la escritura, en la imposibilidad de escribir una novela, anuncian y escriben "el libro por venir", que no es otro 
que aquel que surge mientras se escribe, mientras se lee. Anotar para no olvidar, pero también para ensayar formas otras de literatura.

Barthes, Roland. La preparación de la novela. México: Siglo XXI Editores, 2005.

Bataille, Georges. La felicidad, el erotismo y la literatura. Ensayos 1944-1961. Buenos Aires: Adriana Hidalgo editora, 2008.

Blanchot, Maurice. El espacio literario. Madrid: Editora Nacional, 2002. . El libro por venir. Madrid: Arena Libros, 2005.

Foffani, Enrique. "Tamara Kamenszain: La poesía como novela luminosa”, en Kamenszain, Tamara. La novela de la poesía. Buenos Aires: Adriana Hidalgo Editora, 2012.

Gandolfo, Elvio (comp.) Mario Levrero. Un silencio menos. Buenos Aires: Mansalva, 2013.

Garramuño. "La prosa de la poesía”. In: Mundos en común: ensayos sobre la inespecificidad en el arte. Buenos Aires: Fondo de Cultura Económica, 2015.

Kamenszain, Tamara. La novela de la poesía, en La novela de la poesía. Buenos Aires: Adriana Hidalgo editora, 2012.

. "Narrarse a sí mismo, versificar al otro. Los casos Molloy- Kamenszain”, conferencia en USP 2012, In: https://www. 
AVATAReS DE LA PALABRA ESCRITA: LA NOTACIÓN COMO POSIBILIDAD NARRATIVA. UNA LECTURA DE LEVRERo, Molloy y Kamenszain

MARÍa Victoria RupIL

youtube.com/watch?v=SqDE6SODRG4

Kanzepolsky, Adriana. Nas margens da morte. Tamara Kamenszain: escrita e luto. En prensa.

- "Su 'acumulación primitiva': Desarticulaciones de

Sylvia Molloy”. In: Hispámerica 129, 2014, 23-32.

Lacoue-Labarthe, Philippe. La poesía como experiencia. Madrid: Arena Libros, 2006.

Levrero, Mario. Diario de un canalla-Burdeos/1972. Buenos Aires: Mondadori, 2013. . Irrupciones. Buenos Aires: Criatura Editora, 2013. - La novela luminosa, Buenos Aires: Mondadori, 2010.

Molloy, Silvia. En breve cárcel. Buenos Aires: Fondo de Cultura Económica, 2011. . Desarticulaciones. Buenos Aires: Eterna Cadencia, 2010.

Oviedo, Matías Borg. La literatura como forma de lo común: una aproximación a dos novelas de Mario Levrero. Trabajo Final de Licenciatura, Escuela de Letras, FFyH/UNC, Córdoba, 2014.

Saer, Juan José. Juan José Saer por Juan José Saer. Buenos Aires: Editorial Celtia, 1986. 
